Maurício Reginaldo Alves dos Santos ${ }^{1 *}$, Renato Abreu Lima ${ }^{1,2}$, Maria das Graças Rodrigues Ferreira ${ }^{1}$, Josilene Félix Rocha ${ }^{1}$, Marcelo Curitiba Espíndula ${ }^{1}$, Enrique Anastácio Alves ${ }^{1}$

\title{
Acclimatization of micropropagated plantlets of Coffea canephora
}

\begin{abstract}
Coffea canephora is the predominant species in the state of Rondônia, due to its adaptation to soil and climatic conditions in the region. The acclimatization comprises a set of techniques and procedures that are designed to adapt plantlets to field conditions, heterotrophic to autotrophic condition. This work aimed to evaluate conditions of acclimatization of plantlets of $C$. canephora in relation to the initial stages of seedling development, levels of shading and acclimatization period. In the first experiment, we used three stages of micropropagated plants: "torpedoes", "sprouted" and "seedling" and two levels of shading, 30 and 50\% in 3 x 2 factorial. The plants were weighed and placed individually in cells containing the trays Plantmax ${ }^{\circledR}$. After 30 days, there was survival, plant length, leaf number and fresh weight. The second experiment evaluated three periods of acclimatization at 30,45 and 60 days, after the seedlings were transferred to field conditions in plastic bags. After 90 days of the deployment of the experiment, there was survival, plant length, leaf number and the ratio between initial and final weight of the seedlings. The developmental stage "seedlings" resulted in increased survival and plant development stages in relation to "torpedo" and "sprouted." The shading of 50\% resulted in increased survival and plant growth than $30 \%$. The acclimatization period of 30 days did not differ significantly from the periods of 45 and 60 days, the most suited for this application.
\end{abstract}

Key-words: Plant tissue culture, micropropagation, Coffea canephora, survival.

\section{Aclimatização de mudas micropropagadas de Coffea canephora}

\section{RESUMO}

A aclimatização compreende um conjunto de técnicas e procedimentos que têm por objetivo adaptar mudas micropropagadas às condições de campo, da condição heterotrófica para autotrófica. Por meio deste trabalho, objetivou-se avaliar condições de aclimatização de mudas micropropagadas de C. canephora, em relação aos estádios de desenvolvimento inicial das plântulas, níveis de sombreamento e período de aclimatização. No primeiro experimento, utilizou-se três estádios de plantas micropropagadas: "torpedos"; "germinadas" e "plântulas"; e dois níveis de sombreamento, 30 e $50 \%$, em fatorial 3 × 2 . As plantas foram pesadas e acondicionadas individualmente em células de bandejas contendo o substrato Plantmax ${ }^{\circledR}$. Após 30 dias, determinou-se a sobrevivência, o comprimento das plantas, o número de folhas e o peso fresco. No segundo experimento, avaliou-se três períodos de aclimatização, 30, 45 e 60 dias, após os quais as plântulas foram transferidas para condições de campo, em sacolas de plástico. Após 90 dias da implantação do experimento, observou-se sobrevivência, comprimento das plantas, número de folhas e razão entre peso inicial e final das mudas obtidas. O estádio de desenvolvimento "plântula" resultou em maior sobrevivência e desenvolvimento vegetal em relação aos estádios "torpedo" e "germinada". O sombreamento de $50 \%$ resultou em maior sobrevivência e desenvolvimento vegetal que $30 \%$. O período de aclimatização de 30 dias não diferiu significativamente dos períodos de 45 e 60 dias, sendo o mais indicado neste caso.

Palavras-chave: Coffea canéfora, cultura de tecidos vegetais, embriogênese somática.

\footnotetext{
*Autor para correspondência.

${ }^{1}$ Embrapa Rondônia; BR 364, km 5,5, Caixa Postal 12; Porto Velho - RO - Brasil, mauricio@ cpafro.embrapa.br

${ }^{2}$ Universidade Federal de Rondônia; 78900-000; Porto Velho - RO - Brasil.
} 


\section{INTRODUÇÃO}

O café é um importante produto do agronegócio brasileiro, com um valor histórico e, principalmente, econômico para o Brasil, que destaca-se como o principal produtor mundial (Conab, 2013). A produção cafeeira do Brasil está distribuída principalmente nos estados de Minas Gerais, Espírito Santo, São Paulo, Paraná, Rondônia e Bahia (Conab, 2013). Em Rondônia, seu plantio ocorre desde a década de 1970, constituindo-se na base econômica de pequenas e médias propriedades (Oliveira; Holanda-Filho, 2009).

O estado de Rondônia ocupa o quinto lugar entre os maiores produtores de café do País e é o segundo maior produtor de café do tipo canéfora (Coffea canephora). Isso se deve a boa adaptação a regiões baixas, elevada produção, rusticidade e vigor, além de ser resistente ao nematóide das galhas, à seca, devido ao exuberante sistema radicular, e resistente ao agente da ferrugem (Hemileia vastatrix Berk.), que tem se mostrado bastante agressivo nas regiões produtoras de café, sendo considerado o principal problema fitossanitário da cultura (Ferrão et al., 2004). Conforme Silva et al. (2012) os períodos de coleta de café influenciam a variação da abundância de fauna, riqueza e diversidade de grupos da fauna edáfica, onde na serrapilheira é o compartimento onde se extrai mais indivíduos.

Para que o estado de Rondônia se mantenha com uma cafeicultura estável e economicamente produtiva, é importante colocar para os agricultores variedades de café com boa adaptação ao clima da região e resistentes às principais pragas e doenças. Para isso, novos métodos biotecnológicos têm sido introduzidos para auxiliar os programas de melhoramento genético de cafeeiros, e têm se mostrado bastante promissores. Técnicas de cultura de tecidos, como a embriogênese somática, podem auxiliar a micropropagação acelerada de clones, a manutenção de híbridos e a difusão de novas cultivares aos agricultores e pequeno espaço de tempo (Torres et al., 1998).

A utilização de mudas obtidas por micropropagação in vitro oferece inúmeras vantagens, dentre elas a redução do espaço e do tempo necessários para a produção e a oferta de materiais livres de bactérias, fungos, vírus e nematóides (Scaranari, 2006).

Para se estabelecer mudas micropropagadas em condições de campo, estas devem passar por um processo adaptativo, chamado de aclimatização. Esta fase intermediária compreende um conjunto de técnicas e procedimentos que têm por objetivo reduzir o estresse devido à passagem da condição heterotrófica para autotrófica, sendo realizada em viveiro coberto ou casa de vegetação, utilizando-se recipientes contendo substratos (Guerra e Nodari, 2006).

Considerando a necessidade crescente de utilização de práticas agrícolas sustentáveis e ambientalmente viáveis, o objetivo com este trabalho foi avaliar o desenvolvimento de mudas micropropagadas de $C$. canephora durante aclimatização em relação aos estádios de desenvolvimento inicial das plantas, níveis de sombreamento e período de aclimatização.

\section{MATERIAL E MÉTODOS Micropropagação}

Os explantes provenientes de brotações micropropagadas foram inicialmente inoculados em meio MS (Murashige e Skoog, 1962) suplementado com reguladores de crescimento, $2 \mathrm{iP}(10 \mu \mathrm{M})$ e AIB $(4,9 \mu \mathrm{M})$, acrescido com $3 \%$ de sacarose, $\mathrm{pH} 5,8$ antes da autoclavagem a $121^{\circ} \mathrm{C}$, durante 20 minutos. Após cinco meses, os calos embriogênicos foram subcultivados em meio MS suplementado com BAP $(4,44 \mu \mathrm{M})$ e AIB $(4,9$ $\mu \mathrm{M})$, em frascos cilíndricos de vidro transparente, com tampa de polipropileno de rosca, contendo 30 $\mathrm{mL}$ de meio de cultura, sob fotoperíodo de 16 horas e temperatura $25 \pm 1^{\circ} \mathrm{C}$.

\section{Aclimatização \\ Experimento 1}

$\mathrm{O}$ presente trabalho foi realizado no Laboratório de Biotecnologia Vegetal e em casa de vegetação da Embrapa Rondônia, em Porto Velho, Rondônia, no período de dezembro de 2010 a maio de 2011 , com coordenadas geográficas de $8^{\circ} 53^{\prime} 20^{\prime \prime}$ de Latitude Sul e 63 06' 40' de Longitude Oeste. De acordo com a classificação climática de Köppen, o clima da região é do tipo Aw' caracterizado como clima tropical chuvoso com média climatológica da temperatura do ar, durante o mês mais frio, superiores a $18^{\circ} \mathrm{C}$, e um período seco bem definido durante a estação de inverno.

As plantas provenientes do material in vitro foram retiradas dos frascos e suas raízes lavadas em água corrente para a retirada do excesso do meio de cultura, a fim de evitar a proliferação de microorganismos. Após a lavagem, as plantas foram acondicionadas em células de bandejas de 
polipropileno contendo substrato Plantmax ${ }^{\circledR}$ em casa de vegetação.

$\mathrm{O}$ experimento foi conduzido em esquema fatorial $3 \times 2$ composto por três estádios de desenvolvimento de explantes de C. canephora, combinado com dois níveis de sombreamento para aclimatização. Os estádios de desenvolvimento foram: 1- torpedo (alongamento do embrião, com ausência de cotilédones); 2- germinadas (apresentando cotilédones sem a presença de raízes) e 3- plântulas (apresentando cotilédones e raízes). Todas estas estruturas apresentavam de 3 a $8 \mathrm{~mm}$ de comprimento. Os níveis de sombreamento foram 30 e $50 \%$. O delineamento experimental foi em blocos casualizados, com três repetições de cinco plantas.

Utilizou-se um explante por célula da bandeja, totalizando 90 explantes, mantidas em casa de vegetação. A irrigação foi feita por aspersão, às 07:30, 09:30, 11:30, 13:30, 15:30 e 17:30 horas, com duração de 15 minutos. Foram registradas temperaturas médias mínimas e máximas de 22 e $32^{\circ} \mathrm{C}$, respectivamente.

As avaliações foram realizadas a cada sete dias após a instalação do experimento, durante 28 dias, por meio dos seguintes parâmetros: sobrevivência, altura da planta (medida da base do caule até o ponto mais alto das folhas), número de folhas e peso fresco. No início e a cada sete dias, durante 28 dias após a instalação do experimento, as plantas tiveram seus pesos frescos determinados por meio de balança analítica e a altura da planta por auxílio de um paquímetro.

Os dados foram submetidos à análise de variância e as médias comparadas pelo teste de Tukey, a 5\%, utilizando-se o software Bioestat 5.0.

\section{Experimento 2 - Períodos de Aclimatização}

Após 28 dias do experimento 1, os resultados indicaram que o estádio de desenvolvimento plântula teve maior desempenho e que suportaram estresse inicial, bem como apresentaram as melhores condições fisiológicas. Por isso, o estádio de plântula foi escolhido para compor o experimento 2. Neste experimento, 90 mudas do estádio plântula obtidas in vitro $\mathrm{e}$ que apresentavam raízes vigorosas foram transplantadas individualmente para bandejas de polipropileno contendo o substrato Plantmax ${ }^{\circledR}$ em sombreamento de $50 \%$. Os tratamentos foram 30 , 45 e 60 dias de aclimatização, após os quais, 30 mudas, a cada período avaliado, foram transferidas para sacos plásticos de cinco litros contendo substrato recomendado para produção de mudas de café canéfora (Marcolan et al., 2009). Estas sacolas foram mantidas em condições de campo.

Os parâmetros avaliados foram: sobrevivência, comprimento da planta (da extremidade da raiz ao ápice da planta), número de folhas, razão peso inicial e final, obtidos aos 90 dias após a implantação do experimento no início da aclimatização. $\mathrm{O}$ delineamento experimental utilizado foi em blocos casualizados, com seis repetições de cinco plantas.

A razão peso final/peso inicial, comprimento final/comprimento inicial e número de folhas final/inicial foram calculados pela seguinte fórmula:

$\mathrm{RDF} / \mathrm{DI}=\underline{\mathrm{DF}-\mathrm{DI}} \times 100$

DI

Em que:

RDF/DI: Razão entre a determinação final e a determinação inicial

DF: Determinação final

DI: Determinação inicial

Os dados foram submetidos à análise de variância e as médias comparadas pelo teste de Tukey, a 5\%, utilizando-se o software BioEstat 5.0.

\section{RESULTADOS E DISCUSSÃO Experimento 1}

O sombreamento de $50 \%$ resultou em taxas de sobrevivência superiores às observadas no sombreamento $30 \%$, provavelmente devido à maior perda de água por transpiração e evaporação neste último (Tabela 1). 
Tabela 1. Porcentagens de sobrevivência de plantas de $C$. canephora, após 28 dias de aclimatização, em relação aos estádios de desenvolvimento inicial dos explantes e aos níveis de sombreamento. Embrapa Rondônia, Porto Velho, 2011

\begin{tabular}{cccc}
\hline Estádio de desenvolvimento & \multicolumn{3}{c}{ Sombreamento } \\
\cline { 2 - 4 } inicial dos explantes & $\mathbf{3 0 \%}$ & $\mathbf{5 0 \%}$ & Médias \\
\hline Torpedo & $13,33 \mathrm{bC}$ & $53,33 \mathrm{aC}$ & $33,33 \mathrm{C}$ \\
Germinada & $53,33 \mathrm{bB}$ & $66,66 \mathrm{aB}$ & $60,00 \mathrm{~B}$ \\
Plântula & $93,33 \mathrm{bA}$ & $100,00 \mathrm{aA}$ & $96,67 \mathrm{~A}$ \\
Médias & $53,33 \mathrm{~b}$ & $73,33 \mathrm{a}$ & 63,33 \\
\hline
\end{tabular}

*Médias seguidas de mesma letra maiúscula, na coluna, e mesma letra minúscula, na linha, não diferem entre si pelo teste de Tukey $(\mathrm{p} \leq 0,05)$.

Em geral, durante a aclimatização, procura-se identificar o menor nível de sombreamento aceitável, pois quanto mais se assemelharem às condições de campo, menor será o impacto entre estas fases. Porém, neste experimento, identificouse que o nível de $30 \%$ de sombreamento não é adequado, resultando em aproximadamente 50\% dos explantes mortos. Pode-se sugerir que $50 \%$ seja adequado na fase de retirada do laboratório, mas há necessidade de uma fase subsequente de aclimatização.

Em relação ao estádio de desenvolvimento inicial dos explantes, observou-se que, independentemente do nível de sombreamento (não foi observada interação significativa entre os fatores estudados), a sobrevivência foi intensamente influenciada, podendo-se afirmar que o estádio de plântula é o mais adequado para a aclimatização, com sobrevivência média de $96,67 \%$.

Santana et al. (1996), avaliando a adaptabilidade durante a aclimatização de plântulas de C. arabica obtidas por embriogênese somática, observaram que plantas com até quatro pares de folhas podem se adaptar e desenvolver adequadamente ao ambiente ex vitro, com sobrevivência de $90 \%$, utilizando sombreamento de 50 a $80 \%$, permitindo assim o seu crescimento, concordando com os resultados obtidos no presente trabalho.

Resultados semelhantes foram encontrados por Carvalho et al. (1999) durante a aclimatização de brotações micropropagadas de cafeeiro $(C$. arabica) cultivar Catuaí, com dois a três centímetros de altura. Os autores observaram $100 \%$ de sobrevivência das mudas, e associaram o intenso desenvolvimento da parte aérea com o desenvolvimento do sistema radicular.

$\mathrm{O}$ sistema radicular mais desenvolvido, peculiaridade das plântulas em relação aos outros estádios estudados, provavelmente é o diferencial que resultou em maior sobrevivência destas, considerando-se que o fator ambiental mais drasticamente alterado na aclimatização é a umidade relativa e a disponibilidade de água para absorção pela planta. Assim, a alta sobrevivência observada no estádio plântula sugere tolerância das mesmas ao estresse hídrico neste período e que as raízes produzidas na etapa de micropropagação desta espécie são funcionais, existindo pêlos radiculares e conexões vasculares, provendo água e nutrientes para a planta.

Etienne-Barry et al. (1999) realizaram um trabalho semelhante ao presente estudo, porém envolvendo a aclimatização de embriões somáticos de $C$. arabica produzidos em biorreatores, também nos estádios de desenvolvimento torpedos, germinadas e plântulas. Após 30 dias de experimento, os autores observaram média de sobrevivência de $60 \%$ das mudas e que o estádio de desenvolvimento plântula foi o que obteve maior porcentagem de sobrevivência (78\%).

Resultados semelhantes foram encontrados por Santos (2001), na qual afirma ser adequada a aclimatização das plântulas de $C$. arabica 'Acaiá Cerrado', 'Rubi' e 'Topázio' e C. canephora 'Apoatã' utilizando, sequencialmente, em períodos de sete dias, telas de sombrite de 70, 50, 50 e $30 \%$ de sombreamento, obtendo assim sobrevivência de 80 a $90 \%$.

O sombreamento de $50 \%$ promoveu maior altura de plantas apenas quando foram utilizados explantes na fase torpedo. Para os demais estádios, os explantes não apresentaram diferença entre os sombreamentos. No entanto, para os estádios de desenvolvimento inicial dos explantes, em ambos os níveis de sombreamento, a fase de plântula proporcionou maior altura que o estádio germinada, e esta, por sua vez, proporcionou maior altura que o estádio torpedo (Tabela 2). O maior desempenho dos estádios plântula e germinada estão relacionados ao maior tamanho inicial dos explantes. 
Tabela 2. Altura (mm) das plantas de C. canephora, após 28 dias de aclimatização, em relação aos estádios de desenvolvimento inicial dos explantes e aos níveis de sombreamento. Embrapa Rondônia, Porto Velho, 2011.

\begin{tabular}{cccc}
\hline Estádio de desenvolvimento & \multicolumn{3}{c}{ Sombreamento } \\
\cline { 2 - 4 } inicial dos explantes & $\mathbf{3 0 \%}$ & $\mathbf{5 0 \%}$ & Médias \\
\hline Torpedo & $4,59 \mathrm{bC}$ & $9,02 \mathrm{aC}$ & $6,81 \mathrm{C}$ \\
Germinada & $11,85 \mathrm{aB}$ & $13,90 \mathrm{aB}$ & $12,88 \mathrm{~B}$ \\
Plântula & $24,80 \mathrm{aA}$ & $25,16 \mathrm{aA}$ & $24,98^{\mathrm{a}}$ \\
Médias & $13,75 \mathrm{a}$ & $16,03 \mathrm{a}$ & 14,89 \\
\hline
\end{tabular}

*Médias seguidas de mesma letra maiúscula, na coluna, e mesma letra minúscula, na linha, não diferem entre si pelo teste de Tukey $(\mathrm{p} \leq 0,05)$.

O sombreamento de $50 \%$ e o estádio de desenvolvimento plântula promoveram as maiores médias que o sombreamento de $30 \%$ para o parâmetro números de folhas (Tabela 3), confirmando o fato de serem os mais adequados para a aclimatização de plântulas de C. canephora.

Tabela 3: Número de folhas das plantas de $C$. canephora, após 28 dias de aclimatização, em relação aos estádios de desenvolvimento inicial dos explantes e aos níveis de sombreamento. Embrapa Rondônia, Porto Velho, 2011.

\begin{tabular}{cccc}
\hline Estádio de desenvolvimento & \multicolumn{3}{c}{ Sombreamento } \\
\cline { 2 - 4 } inicial dos explantes & $\mathbf{3 0 \%}$ & $\mathbf{5 0 \%}$ & Média \\
\hline Torpedo & $1,50 \mathrm{aC}$ & $2,00 \mathrm{aC}$ & $1,75 \mathrm{C}$ \\
Germinada & $3,25 \mathrm{aB}$ & $3,80 \mathrm{aB}$ & $3,52 \mathrm{~B}$ \\
Plântula & $5,42 \mathrm{aA}$ & $6,06 \mathrm{aA}$ & $5,74^{\mathrm{a}}$ \\
Médias & $3,39 \mathrm{a}$ & $3,95 \mathrm{a}$ & 3,67 \\
\hline
\end{tabular}

*Médias seguidas de mesma letra maiúscula, na coluna, e mesma letra minúscula, na linha, não diferem entre si pelo teste de Tukey $(\mathrm{p} \leq 0,05)$.

Moreira et al. (2006) afirmam que o número de folhas é uma característica importante, pois mudas com maior número de folhas tem maior índice de sobrevivência de plantas no campo, uma vez que estas são as estruturas responsáveis pela captação de energia solar e produção de compostos orgânicos por meio da fotossíntese.
Os maiores pesos frescos foram aqueles em que as mudas estavam sob sombreamento de $50 \%$, no estádio de plântula. $\mathrm{O}$ peso fresco do estádio de desenvolvimento germinada não diferiu, nos sombreamento de 30 e $50 \%$ (Tabela 4).

Tabela 4. Peso fresco das plantas de C. canephora, após 28 dias de aclimatização, em relação aos estádios de desenvolvimento inicial dos explantes e aos níveis de sombreamento. Embrapa Rondônia, Porto Velho, 2011.

\begin{tabular}{cccc}
\hline Estádio de desenvolvimento & \multicolumn{3}{c}{ Sombreamento } \\
\cline { 2 - 4 } inicial dos explantes & $\mathbf{3 0 \%}$ & $\mathbf{5 0 \%}$ & Médias \\
\hline Torpedo & $18,50 \mathrm{bC}$ & $28,34 \mathrm{aC}$ & $23,42 \mathrm{C}$ \\
Germinada & $43,55 \mathrm{aB}$ & $47,13 \mathrm{aB}$ & $45,34 \mathrm{~B}$ \\
Plântula & $54,88 \mathrm{bA}$ & $96,32 \mathrm{aA}$ & $75,60^{\mathrm{a}}$ \\
Médias & $38,97 \mathrm{~b}$ & $57,26 \mathrm{a}$ & 38,12 \\
\hline
\end{tabular}

*Médias seguidas de mesma letra maiúscula, na coluna, e mesma letra minúscula, na linha, não diferem entre si pelo teste de Tukey $(\mathrm{p}<0,05)$.

Carvalho et al. (1999), em trabalho de aclimatização de $C$. arabica, verificaram que plantas com raízes apresentaram uma tendência de maior massa de matéria fresca da parte aérea $(86,40 \mathrm{~g})$ e número de folhas $(13,34)$ em relação às plantas sem raízes. Além disso, os autores relatam que as raízes produzidas na condição in vitro não morrem após o transplantio para a condição ex vitro. No entanto, evidencia-se também que essas 
raízes não são capazes de proporcionar um melhor desenvolvimento da parte aérea.

As raízes do cafeeiro, além de cumprir funções como absorção e condução de água e minerais, também têm função de suporte e de reserva. Portanto, as raízes são centros obrigatórios de importação de fotoassimilados, ou drenos, armazenando o produto da fotossíntese quando o consumo da planta para o crescimento e a frutificação são menores que a produção. Grandes prejuízos aos cafeeiros podem ocorrer na situação inversa, ou seja, quando a produção de fotoassimilados é menor que o consumo da planta, pois as raízes têm menor força de dreno que as folhas novas e frutos, podendo ocorrer à paralisação do crescimento e até mesmo a morte do sistema radicular (Rena e Maestri, 1986).

\section{Experimento 2 - Períodos de Aclimatização}

A sobrevivência das plantas não foi significativamente afetada pelo tempo de aclimatização (Tabela 5). Considerando-se apenas este aspecto, o período de 30 dias seria o mais recomendável, uma vez que representa economia de tempo em relação aos outros períodos testados.

Tabela 5. Porcentagens de sobrevivência, razão comprimento final/inicial (RCF/CI), razão número de folhas final/inicial (RNFF/NFI) e razão peso final/inicial (\%) (RPF/RPI) de plantas de C. canephora, após aclimatização em diferentes períodos de tempo, avaliadas 90 dias após a implantação do experimento. Embrapa Rondônia, Porto Velho, 2011.

\begin{tabular}{ccccc}
\hline $\begin{array}{c}\text { Períodos de } \\
\text { aclimatização }\end{array}$ & Sobrevivência $(\%)^{*}$ & RCF/CI & RNFF/NFI & RPF/RPI \\
\hline 30 & $95,0 \mathrm{a}$ & $137,1 \mathrm{a}$ & $81,4 \mathrm{a}$ & $122,4 \mathrm{a}$ \\
45 & $100,0 \mathrm{a}$ & $36,2 \mathrm{~b}$ & $22,2 \mathrm{~b}$ & $42,9 \mathrm{~b}$ \\
60 & $96,7 \mathrm{a}$ & $3,6 \mathrm{c}$ & $3,3 \mathrm{c}$ & $8,5 \mathrm{c}$ \\
\hline
\end{tabular}

*Médias seguidas de mesma letra minúscula, na coluna, não diferem entre si pelo teste de Tukey $(\mathrm{p}<0,05)$.

Os resultados obtidos na presente pesquisa se apresentam de forma semelhante aos de Ribeiro et al. (2010), nas quais observou que o percentual de plântulas sobreviventes foi de $100 \%$, após aclimatização de 45 dias.

Ao sofrer mudança abrupta de ambiente, normalmente as plantas apresentam redução do crescimento até que se adaptem às novas condições, podendo levar de dias a semanas até que retornem ao crescimento. Assim, a redução de perdas por morte, associada ao rápido crescimento de mudas tanto no período de aclimatização quanto em campo são fatores que podem contribuir significativamente para que mudas micropropagadas cheguem ao setor produtivo de forma mais rápida e barata (Pereira; Fortes, 2004). Com relação à razão entre número de folhas inicial e final, também se observou que este parâmetro foi inversamente proporcional ao tempo de aclimatização. Notando-se que aos 30 dias de aclimatização de $C$. canephora a razão entre número de folhas inicial e final foi de $81,4 \%$.

$\mathrm{O}$ número de folhas, totalmente formadas e desenvolvidas em condições de campo, é uma variável importante, pois têm influência sobre outras variáveis de crescimento e desenvolvimento, tais como a massa fresca e seca da plântula.
Rocha et al. (2009) reforça que mudas micropropagadas quando aclimatizadas em condições de campo, pode resultar em maiores números de folhas quando estas mudas apresentam inicialmente 2 a 4 pares de folhas.

$\mathrm{Na}$ aclimatização, a planta começa a ativar seus fotossistemas 1 e 2 e a formação de cloroplastos, entre outros fatores fisiológicos, para que todo este processo seja perfeito e a planta se constitua de todas as suas estruturas funcionais, essenciais para seu desenvolvimento. Por isso, a fase de aclimatização não pode ser omitida, pois as novas condições devem ser repassadas às plantas de forma progressiva (Wetztein e Sommer, 1982).

A razão entre os pesos frescos inicial e final das plantas confirma o fato de que o desenvolvimento vegetal aumentou com o decréscimo do tempo de aclimatização, o que leva à conclusão de que os períodos de tempo de 45 e 60 dias foram excessivos, inibindo o crescimento vegetal devido, provavelmente, ao sombreamento das plantas, aspectos nutricionais e o substrato utilizado.

Berilli et al. (2010) afirmam que plantas micropropagadas quando aclimatizadas em condições de campo tendem a apresentam maiores médias de ganho de massa fresca com 30 a 60 dias. É de se esperar que, uma vez que a planta já esteja devidamente aclimatizada, as condições de 
irrigação e sombreamento impostas devem ser controladas para que haja o crescimento da planta. Oliveira et al. (2011) afirma que ainda há muito a ser elucidado sobre a aclimatização de clones de café. No entanto, existe uma tendência de mudas aclimatizadas com a base suporte possuírem maior vigor vegetativo e massa de raízes densas, que podem ser atribuídos a um acúmulo de nutrientes e na base-suporte. Porém, deformidades significativas na raiz principal foram encontradas, e que serão prejudiciais na futura lavoura. Essas alterações também ocorreram em mudas com ausência do aparato, em menor frequência.

\section{CONCLUSÕES}

O estádio de desenvolvimento "plântula" resulta em maior sobrevivência e desenvolvimento vegetal durante a aclimatização de mudas micropropagadas de $C$. canephora.

O sombreamento de $50 \%$ resulta em maior sobrevivência e desenvolvimento vegetal na aclimatização de mudas de $C$. canephora.

O período de 30 dias é o mais indicado para aclimatização de mudas micropropagadas in vitro.

\section{AGRADECIMENTOS}

A CAPES pela concessão de bolsa de mestrado a Renato Abreu Lima.

\section{REFERÊNCIAS}

BERILli, S. S.; CARVALHO, A. J. C.; FREITAS, S. J.; BERILLI, A. P. C. G.; SANTOS, P. C. Avaliação do desenvolvimento de diferentes tamanhos de mudas micropropagadas de abacaxizeiro, após aclimatização. Revista Brasileira de Fruticultura, v. 3, n. 2, p. 125-131, 2010.

CARVALHO, G. R.; PASQUAL, M.; RESENDE, E.; SCARANTE, M. J. Aclimatização de plântulas de cafeeiro (Coffea arabica L.) propagadas "in vitro". Ciência e Agrotecnologia, v. 23, n. 3, p. 483-490, 1999.

COMPANHIA NACIONAL DE ABASTECIMENTO. Acompanhamento da Safra Brasileira, Café Safra 2013 segunda estimativa, maio/2013. Brasília: Conab, 2013. 20 .

ETIENNE-BARRY， D.; BERTRAND， B.; VASQUEZ, N.; ETIENNE, H. Direct sowing of
Coffea arabica somatic embryos mass-produced in a bioreactor and regeneration of plants. Plant Cell Reports, v. 19, n. 2, p. 111-117, 1999.

FERRÃO, R. G. FONSECA， A. F. A. da; FERRÃO, M. A. G.; DEMUNER, L. H.; VERDIN FILHO, A. C.; VOLPI, P. S.; MARQUES, E. M. G.; ZUCATELI, F. Café Conilon: técnicas de produção com variedade melhoradas. Vitória: Incaper, 2004. 60p.

GUERRA, M. P. e NODARI, R. O. Material didático de apoio à disciplina de Biotecnologia. Santa Catarina: Universidade Federal de Santa Catarina. 2006. Disponível em <http://www.cca.ufsc.br/lfdgv/Apostila.htm> Acesso em 27 mar. 2011.

MARCOLAN, A. L.; RAMALHO, A. R.; MENDES, A. G.; TEIXEIRA, C. A. D.; FERNANDES, C. F.; COSTA, J. N. M.; VIEIRAJÚNIOR, J. R.; OLIVEIRA, S. J. M.; FERNANDES, S.R ; VENEZIANO, W. Cultivo dos cafeeiros Conilon e Robusta para Rondônia. 3.Ed. Porto Velho: EMBRAPA RONDÔNIA, 2009. 72p.

MOREIRA, M. A.; CARVALHO, J. G.; PASQUAL, M.; FRÁGUAS, C. B.; SILVA, A. B. Efeito de substratos na aclimatização de mudas micropropagadas de abacaxizeiro cv. Pérola. Ciência e Agrotecnologia, v. 30, n. 5, p. 875-879, 2006.

MURASHIGE, T. e SKOOG, F. A revised medium for rapid grow and bioassays with tobacco tissue cultures. Physiologia Plantarum, v. 15, n. 3, p. 473-497, 1962.

OLIVEIRA, S. J. M. e HOLANDA-FILHO, Z. F. Aspectos econômicos, ambientais e sociais da produção cafeeira em diferentes sistemas em Rondônia. Porto Velho: Embrapa Rondônia, 2009, 6p. (Embrapa Rondônia. Comunicado Técnico, 351).

OLIVEIRA， K. C.; GUERREIRO-FILHO, O.; BRAGHINI, M. T.; FERREIRA, J. M. G.; DEBIASIS, C. Uso de base suporte na aclimatização de cafeeiros propagados in vitro. In: SIMPÓSIO DE PESQUISA DOS CAFÉS DO BRASIL, Araxá, 2011. Anais... Araxá: Embrapa café, 2011. p. 22-25. 
PEREIRA, J. E. S. e FORTES, G .R. L. Produção de mudas pré-básicas de batata por estaquia a partir de plantas micropropagadas. Horticultura Brasileira, v. 22, n. 2, p. 185-191, 2004.

RENA, A. B. e MAESTRI, M. Fisiologia do cafeeiro. In: SIMPÓSIO SOBRE FATORES QUE AFETAM A PRODUTIVIDADE DO CAFEEIRO, Poços de Caldas, 1986. Anais... Piracicaba: Potafós, 1986. p. 13-85.

RIBEIRO, J. M.; CASTRO, J. M. C.; RESENDE, G. M.; BASTOS, D. C.; NALI, L. R. Micropropagação e aclimatização de goiabeira 'Paluma'. Petrolina: Embrapa Semiárido, 2010. 26p.

ROCHA, E. L. J.; CARVALHO, A. C. P. P.; AZEVEDO, B. M.; MARINHO, A. B.; VIANA, T. V. A.; VASCONCELOS, D. V. Aclimatização de mudas micropropagadas de helicônia em ambiente protegido em função do tipo de substrato. Ciência e Agrotecnologia, v. 33, n. 6, p. 1457-1462, 2009.

SANTANA, N.; CORTÉS, S. J. V.; MONTES, M. S. Adaptación de vitroplantas de embriones somáticos de cafeto $(C$. arabica L.) variedad Catimor (9722). Cultivos tropicales, v. 17, n. 2, p. 83-84, 1996.

SANTOS, A. C. P.; CORDEIRO, A. T.; FIGUEIRA, M. L.; ZANETTI, R. S.; CRUZ, A. C. F.; ZAMBOLIM, L. Calogênese friável em Coffea arabica e C. canephora. In: Simpósio Brasileiro de Pesquisa dos Cafés do Brasil, 2, Vitória. Anais... Brasília: Embrapa Café, 2001. p. 292.

SCARANARI, C.; LEAL, P. A. M.; MAZZAFERA, P. Sombreamento e períodos de aclimatização de mudas micropropagadas de bananeira cv. Grande Naine. Scientia Agrícola, v. 66, n.3, p. 331-337, 2006.

SILVA, J.; JUCKSCH, I.; FERES, C. I. M. A.; TAVARES, R. C. Fauna do solo em sistemas de manejo de café. Journal of Biotechnology and Biodiversity, v. 3, n. 2, p. 59-71, 2012.

TORRES, C. A.; CALDAS, S. C.; BUSO, A. B. Meios nutritivos. In: CALDAS, L.S.; HARIDASAN, P.; FERREIRA, M.E. Cultura de tecidos e transformação genética de plantas. Brasília: EMBRAPA-CNPH/EMBRAPA-SPI, p. 102-106, 1998.

WETZSTEIN, H. Y. e SOMMER, H. E. Leaf anatomy of tissue-cultured Liquidambar styraciflua (Hamamelidaceae) during acclimatization. American Journal of Botany, v. 69, n. 10, p. 1579-1586, 1982.
Recebido: 08/07/2013

Received: 07/08/2013

Aprovado: 05/11/2013 Approved: 11/05/2013 